\title{
ANALISIS KUALITAS PELAYANAN TERHADAP TINGKAT KEPUASAN PELANGGAN
}

\author{
(Studi Kasus di Restoran Jepang X, Jakarta)
}

\author{
Ika Triana, Agung Gita Subakti \\ Bina Nusantara University \\ itriana@binus.edu,agsubakti@binus.edu
}

\begin{abstract}
The purpose of this study is to analyze the service quality toward customer satisfaction at $X$ Japanese Restaurant. The writer is using the descriptive and associative-causal method. 100 people who are visitors to the restaurant were taken as the sample for this research. The analysis that was used are t-test and by verifying the hypothesis, these methods were used to determine the final result or conclusion of the study. This study showed that customer satisfaction is $75,1 \%$ influenced by service quality and it also reveals a very strong relation between service quality and customer satisfaction at $X$ Japanese Restaurant.
\end{abstract}

Keywords- Service Quality; Customer Satisfaction; Restaurant

\section{PENDAHULUAN}

Pada saat ini salah satu industri yang berkembang sangat pesat di Indonesia adalah industri kuliner. Hal ini disebabkan tingginya tingkat konsumsi masyarakat terhadap makanan dan juga kesibukan masyarakat yang padat sehingga menyebabkan kurangnya waktu untuk membuat makanan dan lebih memilih untuk makan di restoran. Oleh karena itu hal ini memberikan peluang besar bagi pengusaha untuk memulai bisnis restoran yang menjual makanan dan minuman yang disesuaikan dengan kesibukan masyarakat.

Dilihat dari tingginya pertumbuhan bisnis restoran pada saat ini, restoran tidak hanya sekedar menjual makanan dan minuman, tetapi juga memberikan kenyamanan yang dapat dilihat dari suasana dan pelayanan restoran sehingga dapat memberikan kepuasan terhadap konsumen. Hal ini merupakan beban bagi para pengusaha yang tidak bisa lagi menjalankan bisnisnya tanpa perhitungan dan perencanaan yang matang, karena semakin bertambahnya pengusaha maka akan semakin meningkat pula tingkat persaingan. Saat ini jenis usaha restoran semakin beragam dan lebih bervariasi, restoran jepang, restoran korea, restoran cina juga restoran fusion cuisine.

Bagi setiap pengusaha yang bergelut di bidang restoran khususnya di daerah Lokasari, mereka harus bersaing dan berlomba-lomba untuk mendapatkan banyak pelanggan. Dalam kondisi persaingan yang ketat, hal utama yang harus diprioritaskan oleh restoran adalah kepuasan pelanggan agar dapat bertahan, bersaing dan menguasai pasar. Kepuasan pelanggan juga merupakan salah satu hal yang penting, karena apabila pelanggan merasa puas akan suatu produk maka yang umumnya terjadi pelanggan akan terus menerus membeli produk tersebut. Sebaliknya, jika pelanggan tidak puas maka mereka cenderung akan beralih ke produk lain. Suatu restoran yang baik juga harus memperhatikan faktor penting lainnya yaitu faktor kualitas pelayanan. Menurut Lewis \& Booms (1983) yang dikutip kembali oleh Fandy Tjiptono (2011) kualitas jasa sebagai ukuran seberapa bagus tingkat layanan yang diberikan mampu sesuai dengan ekspektasi pelanggan.

Menurut Hoffman \& Bareson (1997) yang dikutip kembali oleh Fandy Tjiptono (2011) Kepuasan pelanggan merupakan ukuran spesifik untuk setiap transaksi, situasi atau interaksi yang bersifat jangka pendek, sedangkan kualitas jasa merupakan sikap yang dibentuk dari evaluasi keseluruhan terhadap kinerja perusahaan dalam jangka panjang. Juga menurut Fandy Tjiptono (2011) kualitas berkaitan erat dengan kepuasan pelanggan. Kualitas memberikan dorongan khusus bagi para pelanggan untuk menjalin ikatan relasi saling menguntungkan dalam jangka panjang dengan perusahaan. Juga bila kualitas yang dihasilkan superior dan pangsa pasar yang dimiliki besar, maka profitabilitasnya terjamin.

Restoran Jepang X yang beroperasi sejak tahun 2012 menawarkan makanan dengan konsep Asian fusion yang beragam dan bervariasi. Restoran Jepang X dilengkapi 
dengan fasilitas pendukung antara lain interior restoran yang nyaman dan cozy, jaringan wi-fi yang cepat juga televisi yang menayangkan parabola setiap saat. Yang membedakan restoran Jepang $\mathrm{X}$ dengan restoran lainnya adalah penempatan restorannya dimana restoran ini berdiri diantara restoran dan bar. Lebih jelasnya lagi restoran ini mempunyai konsep bar tetapi dengan harga restoran yang relatif murah. Masalah yang timbul yaitu banyaknya pelanggan asing yang datang dan menggunakan bahasa asing membuat pelayan Jepang $\mathrm{X}$ yang tidak mengerti bahasa asing menjadi sulit untuk berkomunikasi, dan juga ukuran dapur yang terlalu kecil sehingga menyebabkan produk makanan yang keluar terkadang telat, dan juga dikarenakan kurangnya alat yang memadai untuk memproduksi makanan dalam jumlah yang banyak

\section{Metode Penelitian}

Metode penelitian kuantitatif yang akan peneliti gunakan adalah metode penelitian yang bersifat deskriptif dan asosiatif- kausal, serta time horizon yang digunakan adalah cross sectional. Sugiyono (2012:13) menyatakan metode penelitian kuantitatif adalah metode penelitian yang digunakan untuk meneliti pada populasi atau sampel tertentu. Menurut Sugiyono (2012:55) penelitian asosiatif adalah suatu pertanyaan yang bersifat menanyakan hubungan antara dua variabel atau lebih, terdapat tiga bentuk hubungan yaitu hubungan simetris, hubungan kausal dan interaktif/ timbal balik. Penulis memilih menggunakan hubungan kausal yang artinya hubungan yang bersifat sebab akibat.

\section{A. Objek Penelitian}

Penelitian ini dilakukan oleh penulis dengan meneliti tentang kualitas pelayanan, kepuasan pelanggan dan pengaruh kualitas pelayanan terhadap kepuasan pelanggan. Penelitian ini dibagi menjadi dua variabel yaitu variabel independen atau variabel yang mempengaruhi dan variabel dependen atau variabel yang dipengaruhi. Yang menjadi variabel independen adalah kualitas pelayanan (variabel $\mathrm{X}$ ) yang diukur melalui 5 dimensi yaitu daya tanggap ( responsiveness), realibiltas (realibilty), jaminan (assurance), empati (empathy), dan bukti fisik (tangibles) dan variabel dependen adalah kepuasan konsumen ( variabel Y ) yang diukut melalui 5 dimensi yaitu membeli lagi, menceritakan hal-hal yang menarik kepada orang lain mengenai perusahaan, lebih loyal, tidak memperhatikan produk perusahaan lain, dan menawarkan produk atau ide jasa kepada perusahaan. Dalam penelitian ini yang akan menjadi responden atau objek penelitian adalah para tamu yang ada di Restoran Jepang $X$ yang mempunyai populasi sebanyak 27.872 orang.dan dipilih secara acak 100 orang yang akan dijadikan sampel atau responden

\section{B. Operasional Variabel Penelitian}

Pada penelitian ini terdapat dua operasional variabel antara lain variabel independen yaitu kualitas pelayanan $(\mathrm{X})$ dan variabel dependen yaitu kepuasan pelanggan (Y). Menurut Sugiyono (2012:58) variabel adalah segala sesuatu yang berbentuk apa saja yang ditetapkan oleh peneliti untuk dipelajari sehingga diperoleh informasi tentang hal tersebut kemudia ditarik kesimpulannya. Operasional variabel terdiri dari dua variabel yaitu variabel independen dan variabel dependen. Variabel independen atau variabel bebas merupakan variabel yang mempengaruhi atau yang menjadi sebab perubahannya atau timbulnya variabel dependen. Variabel dependen atau variabel terikat merupakan variabel yang dipengaruhi atau yang menjadi akibat, karena adanya variabel bebas. Operasional variabel akan diuraikan dalam tabel berikut:

TABEL 1. OPERASIONAL VARIABEL $X$

\begin{tabular}{|c|c|c|}
\hline Variabel & Dimensi & Indikator \\
\hline \multirow[t]{8}{*}{$\begin{array}{l}\text { Kualitas } \\
\text { Pelayanan }\end{array}$} & $\begin{array}{l}\text { Bukti langsung } \\
\text { (tangibles) }\end{array}$ & $\begin{array}{l}\text { - Karyawan yang } \\
\text { berpenapilan rapi }\end{array}$ \\
\hline & & $\begin{array}{l}\text { - Perlengkapan dan } \\
\text { fasilitas yang } \\
\text { lengkap }\end{array}$ \\
\hline & & $\begin{array}{l}\text { - Kelengkapan } \\
\text { material } \\
\text { komunikasi }\end{array}$ \\
\hline & $\begin{array}{l}\text { Realibilitas } \\
\text { (reliability) }\end{array}$ & $\begin{array}{l}\text { - Kemampuan } \\
\text { untuk } \\
\text { melaksanakan } \\
\text { pelayanan yang } \\
\text { dapat diandalkan } \\
\text { dan akurat }\end{array}$ \\
\hline & $\begin{array}{l}\text { Daya tanggap } \\
\text { (responsiveness) }\end{array}$ & $\begin{array}{l}\text { Bersedia } \\
\text { membantu } \\
\text { pelanggan } \\
\end{array}$ \\
\hline & & $\begin{array}{l}\text { Memberikan } \\
\text { pelayanan yang } \\
\text { cepat }\end{array}$ \\
\hline & $\begin{array}{l}\text { Jaminan } \\
(\text { assurance })\end{array}$ & $\begin{array}{l}\text { Memiliki } \\
\text { kemampuan yang } \\
\text { dibutuhkan dan } \\
\text { pengetahuan } \\
\text { untuk } \\
\text { melaksanakan } \\
\text { pelayanan }\end{array}$ \\
\hline & $\begin{array}{l}\text { Empati } \\
\text { (empathy) }\end{array}$ & $\begin{array}{l}\text { Kesopanan, } \\
\text { menghormati } \\
\text {,perhatian dan } \\
\text { keramah-tamahan } \\
\text { dari karyawan }\end{array}$ \\
\hline
\end{tabular}

Sumber: Sugiyono (2012:149) 
TABEL 2. OPERASIONAL VARIABEL Y

\begin{tabular}{|c|c|c|}
\hline Variabel & Dimensi & Indikator \\
\hline \multirow[t]{5}{*}{$\begin{array}{l}\text { Kepuasan } \\
\text { Pelanggan }\end{array}$} & $\begin{array}{l}\text { Membeli produk } \\
\text { baru yang } \\
\text { ditawarkan }\end{array}$ & Membeli lagi \\
\hline & $\begin{array}{l}\text { Merekomendasikan } \\
\text { produk }\end{array}$ & $\begin{array}{l}\text { Menceritakan } \\
\text { hal-hal yang } \\
\text { menarik kepada } \\
\text { orang lain } \\
\text { mengenai } \\
\text { perusahaan }\end{array}$ \\
\hline & Tetap loyal & Lebih loyal \\
\hline & $\begin{array}{l}\text { Bersedia membayar } \\
\text { lebih }\end{array}$ & $\begin{array}{l}\text { Tidak } \\
\text { memperhatikan } \\
\text { produk } \\
\text { perusahaan lain }\end{array}$ \\
\hline & Memberi masukan & $\begin{array}{l}\text { Menawarkan } \\
\text { produk atau ide } \\
\text { jasa kepada } \\
\text { perusahaan }\end{array}$ \\
\hline
\end{tabular}

Sumber: Kotler \& Keller (2012:150)

\section{Jenis dan Sumber Data}

\section{Data Primer}

Menurut Sugiyono (2012:193) data primer adalah data yang langsung memberikan data kepada pengumpul data. Untuk mendapatkan data primer peneliti menggunakan metode kuesioner dan wawancara.

\section{Data Sekunder}

Menurut Sugiyono (2012:193) data sekunder merupakan sumber yang tidak langsung memberikan data kepada pengumpul data, misalnya lewat orang lain atau dokumen.

\section{Teknik Pengumpulan Data}

Menurut Sugiyono (2012: 193) teknik pengumpulan data terbagi menjadi:

\section{Interview (wawancara)}

2. Kuisioner (angket)

\section{Observasi}

\section{E. Populasi dan Sampel}

\section{Populasi}

Menurut Sugiyono (2012: 115) populasi adalah wilayah generalisasi yang terdiri atas: obyek/subyek yang mempunyai kualityas dan karakteristik tertentu yang ditetapkan oleh peneliti untuk dipelajari dan kemudian ditarik kesimpulannya.

Sesuai dengan pengertian di atas yang menjadi populasi dari penelitian ini adalah pelanggan Restoran Jepang X.

Tabel 3. Populasi Pengunjung Restoran Jepang X 2013-2014

\begin{tabular}{llc}
\hline No & Bulan & Jumlah Pengunjung \\
\hline 1 & Desember & 2045 \\
2 & Januari & 2121
\end{tabular}

\begin{tabular}{lll}
3 & Februari & 2118 \\
4 & Maret & 2279 \\
5 & April & 2295 \\
6 & Mei & 2230 \\
7 & Juni & 2302 \\
8 & Juli & 2469 \\
9 & Agustus & 2040 \\
10 & September & 2124 \\
11 & Oktober & 2223 \\
12 & November & 2215 \\
\hline & Total & 26461 \\
\hline
\end{tabular}

Sumber: Restoran Jepang X 2013-2014

Berdasarkan data yang diambil dari pihak manajemen Restoran Jepang X, jumlah populasi yang berkunjung mulai dari bulan desember 2013 sampai November 2014 sebanyak 26.461 orang.

\section{Populasi}

Menurut Sugiyono (2012: 116) sampel adalah bagian dari jumlah dan karakteristik yang dimiliki oleh populasi tersebut. Bila populasi besar, dan peneliti tidak mungkin mempelajari semua yang ada pada populasi, maka peneliti dapat menggunakan sampel yang diambil dari populasi itu. Apa yang dipelajari dari sampel itu, kesimpulannya akan dapat diberlakukan untuk populasi. Untuk itu sampel yang diambil dari populasi harus betul-betul mewakili. Dalam penulisan ini, penulis mengambil teknik pengambilan sampel yang bertujuan untuk memudahkan peneliti dalam pengolahan data. Untuk pengambilan sampel digunakan rumus slovin dan didapat jumlah sampel dalam penelitian ini adalah 99,99 yang dibulatkan menjadi 100 responden atau sampel.

\section{F. Populasi dan Sampel}

Menurut Sugiyono (2012:116) teknik sampling merupakan teknik pengambilan sampel. Untuk menentukan sampel yang akan digunakan dalam penelitian, terdapat teknik sampling yang digunakan. Teknik sampling pada dasarnya dapat dikelompokkan menjadi dua yaitu Probability Sampling yang berarti teknik pengambilan sampel tyang memberikan peluang yang sama bagi setiap unsur populasi untuk dipilih menjadi anggota sampel dan Nonprobability Sampling yang berarti teknik pengambilan sampel yang tidak memberi peluang sama bagi setiap unsur populasi untuk dipilih menjadi sampel. Dalam pengambilan sampel ini, penulis akan menggunakan teknik pengambilan sampel dengan menggunakan probability sampling yang fokus pada simple random sampling yang merupakan pengambilan anggota sampel dari populasi dilakukan secara acak tanpa memperhatikan strata yang ada dalam populasi itu. 


\section{G. Teknik Analisa Data}

Penelitian ini adalah untuk meneliti pengaruh kualitas pelayanan terhadap kepuasan pelanggan di Restoran Jepang X maka, model analisis yang digunakan adalah analisis regresi linear sederhana. Menurut Sugiyono (2012:270) Regresi sederhana didasarkan pada hubungan fungsional ataupun kausal satu variabel independen dengan satu variabel dependen. Dapat juga digunakan untuk memutuskan apakah naik dan menurunnya variabel dependen dapat dilakukan melalui naik dan menurunnya variabel independen, atau untuk meningkatkan keadaan variabel dependen dapat dilakukan dengan meningkatkan variabel independen dan sebaliknya.

\section{H. Uji Validitas dan Reliabilitas}

Kuisioner yang baik, harus diuji terlebih dahulu validitas dan reliabilitasnya sehingga hasil penelitian yang diperoleh nantinya akan menjadi baik. Menurut Sugiyono (2012:172) instrumen yang dinyatakan valid dan reliabel adalah: Instrumen yang valid berarti alat ukur yang digunakan untuk mendapatkan data (mengukur) itu valid atau instrumen tersebut dapat digunakan untuk mengukur apa yang seharusnya diukur. Sedangkan instrumen yang reliabel berarti bila digunakan untuk mengukur berkali-kali akan menghasilkan data yang sama.

Dalam pengujian validitas penulis menggunakan jenis validitas konstruk. Menurut Siregar (2013:77) bahwa validitas konstruk adalah validitas yang berkaitan dengan kesanggupan suatu alat ukur dalam mengukur pengertian suatu konsep yang diukurnya. Dalam pengujian validitas konstruk suatu instrument dikatakan valid jika:

1. Koefisien Korelasi Product Moment melebihi 0,3

2. Koefisien Korelasi Product Moment > rtabel $(\alpha: n-2) n=$ jumlah sampel

3. Nilai $\operatorname{sig} \leq \alpha$

Dalam uji validitas konstruk rumus yang digunakan adalah teknik Korelasi Product Moment, yaitu:

$$
r=\frac{n\left(\sum \mathrm{XY}\right)-(\Sigma \mathrm{X})\left(\sum \mathrm{Y}\right)}{\sqrt{\left[\mathrm{n}\left(\sum \mathrm{X}^{2}\right)-\left(\sum \mathrm{X}\right)^{2}\right]\left[\mathrm{n}\left(\sum \mathrm{Y}^{2}\right)-\left(\sum \mathrm{Y}\right)^{2}\right]}}
$$

Keterangan:

$$
\begin{aligned}
\mathrm{n}= & \text { Jumlah Responden } \\
\mathrm{X}= & \text { Skor Variabel } \\
\mathrm{Y}= & \text { Skor total dari variabel untuk responden } \\
& \text { ke-n }
\end{aligned}
$$

Menurut Sugiyono (2012:172) istrumen yang reliabel adalah instrument yang bila digunakan beberapa kali untuk mengukur obyek yang sama akan menghasilkan data yang sama. Uji realibilitas ini dilakukan dengan rumus Cronbach Alpha (siregar 2013:87):

1. Menentukan nilai varian setiap butir pertanyaan

$$
\sigma i^{2}=\frac{\sum \mathrm{X} i^{2}-\frac{\left(\sum \mathrm{X} i\right)^{2}}{n}}{n}
$$

2. Menentukan nilai varian total

$$
\sigma_{\mathrm{t}}^{2}=\frac{\sum \mathrm{X}^{2}-\frac{\left(\sum \mathrm{X}\right)^{2}}{n}}{n}
$$

3. Menentukan reliabilitas instrumen

$$
r_{11}=\left[\frac{k}{k-1}\right]\left[1-\frac{\Sigma \sigma_{b}^{2}}{\sigma_{t}^{2}}\right]
$$

Keterangan:

$\mathrm{n} \quad=$ Jumlah Sampel

$\mathrm{X}_{\mathrm{i}}=$ Jawaban responden untuk setiap butir pertanyaan

$\sum \mathrm{X}=$ Total jawaban responden untuk setiap butir pertanyaan

$\sigma^{2} \mathrm{t}=$ Varian Total

$\sum \sigma_{\mathrm{b}}^{2}=$ Jumlah Varian Butiran

$k=$ Jumlah butir pertanyaan

$\mathrm{R}_{11}=$ Koefisien reliabilitas instrument

Berdasarkan hasil uji validitas dan reliabilitas, diketahui bahwa seluruh item pertanyaan adalah valid dan kuesioner penelitian dinyatakan reliabel.

\section{Hipotesis}

Menurut Sugiyono (2012:93) hipotesis adalah jawaban sementara terhadap rumusan masalah penelitian, oleh karena itu rumusan masalah penelitian biasanya disusun dalam bentuk kalimat pertanyaan. Dikatakan sementara, karena jawaban yang diberikan baru didasarkan pada teori yang relevan, belum didasarkan pada fakta-fakta empiris yang diperoleh melalui pengumpulan data. Jadi hipotesis juga dapat dinyatakan sebagai jawaban teoritis terhadap rumusan masalah penelitian, belum jawaban yang empirik.

Jenis hipotesis yang digunakan oleh penulis adalah hipotesis asosiatif hubungan sebab akibat (kausal). Hipotesis asosiatif kausal merupakan hipotesis yang menyatakan hubungan yang bersifat sebab akibat antara dua variabel atau lebih. 
1. Hipotesis kerja (Ha) yang berarti ada hubungan antar dua variabel.

2. Hipotesis operasional (Ho) yang berarti tidak ada hubungan antar dua variabel.

Berdasarkan pengertian diatas maka hipotesis yang ditujukan oleh penulis adalah sebagai berikut:

1. Hipotesis kerja (Ha): Kualitas pelayanan (variabel $\mathrm{x}$ ) berpengaruh terhadap kepuasan pelanggan (variabel y) di Restoran Jepang $\mathrm{X}$.

2. Hipotesis operasional (Ho): Kualitas pelayanan (variabel $\mathrm{x}$ ) tidak berpengaruh terhadap kepuasan konsumen (variabel y) di Restoran Jepang X.

\section{HASIL PENELITIAN DAN PEMBAHASAN}

A. Profil Responden

TABEL 4. KARAKTERISTIK RESPONDEN

\begin{tabular}{llcc}
\hline \multicolumn{2}{c}{ Karakteristik Responden } & $\begin{array}{c}\text { Jumlah } \\
\text { Orang }\end{array}$ & $\begin{array}{c}\text { Persentase } \\
(\%)\end{array}$ \\
\hline Jenis & Laki Laki & 57 & 57 \\
Kelamin: & Wanita & 43 & 43 \\
\hline Umur: & <20 tahun & 16 & 16 \\
& 20-30 tahun & 51 & 51 \\
& $>30$ tahun & 33 & 33 \\
\hline Pendidikan/ & Pelajar/Mahasis & 12 & 12 \\
Pekerjaan: & wa & 26 & 26 \\
& Karyawan & 30 & 30 \\
& Wiraswasta & 32 & 32 \\
\hline
\end{tabular}

Sumber: Pengolahan data primer (2017)

Melalui Tabel 4 maka diketahui bahwa responden laki-laki dan wanita hampir merata, dengan rentang umur $20-30$ tahun adalah merupakan mayoritas. Dari segi pendidikan kebanyakan adalah yang telah bekerja baik itu karyawan maupun wiraswasta, jika dijumlahkan kedua kelompok ini mencapai $56 \%$.

B. Analisis Deskriptif Variabel

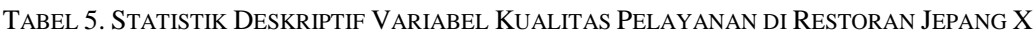

\begin{tabular}{|c|c|c|c|c|c|c|}
\hline \multicolumn{2}{|r|}{ Pertanyaan } & \multirow{2}{*}{$\begin{array}{c}\mathrm{N} \\
100\end{array}$} & \multirow{2}{*}{$\begin{array}{c}\text { Minimum } \\
1\end{array}$} & \multirow{2}{*}{$\begin{array}{c}\text { Maximum } \\
5\end{array}$} & \multirow{2}{*}{$\begin{array}{c}\text { Mean } \\
4.01\end{array}$} & \multirow{2}{*}{$\begin{array}{c}\text { Std. } \\
\text { Deviation }\end{array}$} \\
\hline 1. & $\begin{array}{l}\text { Fasilitas yang ditawarkan oleh Restoran Jepang X } \\
\text { menarik }\end{array}$ & & & & & \\
\hline 2. & $\begin{array}{l}\text { Karyawan Restoran Jepang X memakai seragam } \\
\text { dengan rapi dan profesional }\end{array}$ & 100 & 1 & 5 & 3.84 & 0.90699 \\
\hline 3. & $\begin{array}{l}\text { Menu dan promo Restoran Jepang X dapat mudah } \\
\text { dipahami }\end{array}$ & 100 & 1 & 5 & 3.82 & 0.90319 \\
\hline 4. & $\begin{array}{l}\text { Peralatan yang digunakan Restoran Jepang X selalu } \\
\text { baru }\end{array}$ & 100 & 1 & 5 & 3.78 & 0.91652 \\
\hline 5. & $\begin{array}{l}\text { Karyawan Restoran Jepang X menepati janji yang } \\
\text { dijanjikan }\end{array}$ & 100 & 1 & 5 & 3.93 & 0.83188 \\
\hline 6. & $\begin{array}{l}\text { Karyawan Restoran Jepang X menanggapi instruksi } \\
\text { anda }\end{array}$ & 100 & 1 & 5 & 3.95 & 0.90314 \\
\hline 7. & $\begin{array}{l}\text { Menu dan promo Restoran Jepang X tidak pernah } \\
\text { salah }\end{array}$ & 100 & 1 & 5 & 3.79 & 0.93523 \\
\hline 8. & $\begin{array}{l}\text { Jika ada kerusakan dalam fasilitas segera dibetulkan } \\
\text { oleh Restoran Jepang X }\end{array}$ & 100 & 1 & 5 & 3.88 & 0.89081 \\
\hline 9. & $\begin{array}{l}\text { Karyawan Restoran Jepang X cepat tanggap dan } \\
\text { bersedia dalam merespon permasalahan anda }\end{array}$ & 100 & 1 & 5 & 3.9 & 0.91563 \\
\hline 10. & $\begin{array}{l}\text { Karyawan Restoran Jepang X bersedia menjawab } \\
\text { semua pertanyaan anda }\end{array}$ & 100 & 1 & 5 & 3.82 & 0.95748 \\
\hline 11. & $\begin{array}{l}\text { Jika barang dikembalikan anda tidak harus bayar } \\
\text { barang tersebut }\end{array}$ & 100 & 1 & 5 & 3.84 & 0.99209 \\
\hline 12. & $\begin{array}{l}\text { Karyawan Restoran Jepang } \mathrm{X} \text { bersedia } \\
\text { menginformasikan kapan layanan akan diberikan }\end{array}$ & 100 & 1 & 5 & 3.84 & 1.00222 \\
\hline 13. & Proses transaksi di Restoran Jepang X berjalan lancar & 100 & 1 & 5 & 3.85 & 0.90314 \\
\hline 14. & $\begin{array}{l}\text { Restoran Jepang X selalu melakukan penelitian untuk } \\
\text { meningkatkan pelayanan }\end{array}$ & 100 & 1 & 5 & 3.79 & 0.93523 \\
\hline 15. & $\begin{array}{l}\text { Restoran Jepang X mampu dan bisa menjawab } \\
\text { pertanyaan anda }\end{array}$ & 100 & 1 & 5 & 3.87 & 0.91734 \\
\hline 16. & $\begin{array}{l}\text { Karyawan Restoran Jepang X mengetahui pelayanan } \\
\text { yang dilakukan }\end{array}$ & 100 & 1 & 5 & 3.73 & 0.99346 \\
\hline 17. & $\begin{array}{l}\text { Karyawan Restoran Jepang X memiliki sikap yang } \\
\text { ramah- tamah }\end{array}$ & 100 & 1 & 5 & 3.81 & 1.02193 \\
\hline 18. & $\begin{array}{l}\text { Karyawan Restoran Jepang X tidak bersikap kasar } \\
\text { jika anda bertanya }\end{array}$ & 100 & 1 & 5 & 3.78 & 1.0404 \\
\hline 19. & $\begin{array}{l}\text { Karyawan Restoran Jepang X selalu bersikap sopan } \\
\text { setiap kali anda bertanya }\end{array}$ & 100 & 1 & 5 & 3.84 & 1.00222 \\
\hline 20. & $\begin{array}{l}\text { Karyawan Restoran Jepang X memiliki tata karma } \\
\text { yang bagus }\end{array}$ & 100 & 1 & 5 & 3.79 & 0.97747 \\
\hline & Valid N (Listwise) & & & 100 & & \\
\hline
\end{tabular}


Dari hasil perhitungan SPSS versi 22 dapat dilihat bahwa nilai mean tertinggi berada pada butir pernyataan nomor 1 yaitu 4,01 yang menyatakan bahwa Fasilitas yang ditawarkan oleh Restoran Jepang X menarik. Oleh sebab itu Restoran Jepang X harus mempertahankan indikator pada butir pernyataan nomor 1 . Sedangkan untuk nilai mean terendah yaitu 3,73 berada pada butir pernyataan nomor 16 dengan pernyataan 16. Karyawan Restoran Jepang X mengetahui pelayanan yang dilakukan. Oleh karena itu, Restoran Jepang X harus meningkatkan pengetahuan akan pelayanan yang akan diberikan, seiring dengan meningkatnya kualitas pelayanan maka akan tercipta kepuasan pelanggan yang tinggi.

Tabel 6. Statistik Deskriptif Variabel Kepuasan PelangGan di Restoran JePang X

\begin{tabular}{|c|c|c|c|c|c|}
\hline Pertanyaan & $\mathrm{N}$ & Minimum & Maximum & Mean & Std. Deviation \\
\hline Anda akan kembali ke Restoran Jepang X & 100 & 1 & 5 & 3.73 & 0.97292 \\
\hline $\begin{array}{l}\text { 2. Anda akan merekomendasikan Restoran Jepang X } \\
\text { kepada orang lain }\end{array}$ & 100 & 1 & 5 & 3.77 & 0.94125 \\
\hline $\begin{array}{l}\text { 3. Anda tertarik mencoba menu baru di Restoran } \\
\text { Jepang X }\end{array}$ & 100 & 1 & 5 & 3.81 & 0.90671 \\
\hline $\begin{array}{l}\text { 4. Restoran Jepang X lebih unggul dibandingkan } \\
\text { dengan restoran lain }\end{array}$ & 100 & 1 & 5 & 3.83 & 0.9434 \\
\hline $\begin{array}{l}\text { 5. Anda bersedia memberi saran atau ide kepada } \\
\text { Restoran Jepang X mengenai produk dan layanan }\end{array}$ & 100 & 1 & 5 & 3.86 & 0.96421 \\
\hline Valid N (Listwise) & \multicolumn{5}{|c|}{100} \\
\hline
\end{tabular}

Dari hasil perhitungan SPSS versi 22 dapat dilihat bahwa nilai mean tertinggi berada pada butir pernyataan nomor 25 yaitu 3,86 , yang menyatakan Pelanggan bersedia memberi saran atau ide kepada Restoran Jepang X mengenai produk dan layanan. Kritik dan saran ini merupakan hal yang sangat penting untuk dievaluasi bagi Restoran Jepang $\mathrm{X}$, setelah dievaluasi harus ada perbaikan agar Restoran Jepang $\mathrm{X}$ dapat meningkatkan kualitas pelayanannya yang berpengaruh terhadap kepuasan pelanggannya. Sedangkan untuk nilai mean terendah terdapat pada butir pernyataan nomor 21 yaitu 3,73 dengan pernyataan Pelanggan akan kembali ke Restoran Jepang X. Pernyataan tersebut menyatakan bahwa pelanggan merasa bimbang untuk kembali lagi ke Restoran Jepang X. Oleh karena itu Restoran Jepang $\mathrm{X}$ harus meningkatkan kualitas pelayanannya agar pelanggan mau kembali berlangganan lagi
C. Hasil Tanggapan Wisatawan Terhadap Loyalitas

Tabel 7. Hasil ANalisis Koefisien Determinasi (R SQUARE)

\begin{tabular}{ccc}
\hline $\mathrm{R}$ & R Square & Std. Error of the Estimate \\
\hline 0,866 & 0,751 & 0.43331 \\
\hline \multicolumn{3}{c}{ Sumber: Pengolahan data penelitian (2017) }
\end{tabular}

Dari Tabel 7, pada $R$ menunjukan bahwa hubungan (korelasi) antara kualitas pelayanan dan kepuasan pelanggan adalah 0,866. Menurut Sugiyono (2012:250) tingkat korelasi dan kekuatan hubungan apabila nilai korelasi 0,800,100 maka dikatakan sangat kuat. Besarnya nilai koefisien $R$ square pada tabel 4.11 Model Summary variabel XY sebesar 0,751. Hal ini berarti variabel kepuasan pelanggan (Y) dipengaruhi oleh variabel kualitas pelayanan (X) sebesar $75,1 \%$, sedangkan sisanya $(100 \%$ $75,1 \%$ ) $24,9 \%$ merupakan konstribusi variabel independen lain yang tidak masuk dalam penelitian ini.

TABEL 8. HASIL ANALISIS KoEFISIEN REGRESI

\begin{tabular}{|c|c|c|c|c|c|c|}
\hline \multicolumn{7}{|c|}{ Coefficients } \\
\hline & \multirow{2}{*}{ Model } & \multicolumn{2}{|c|}{ Unstandardized Coefficients } & Standardized Coefficients & \multirow{2}{*}{$\mathrm{t}$} & \multirow{2}{*}{ Sig. } \\
\hline & & $\mathrm{B}$ & Std. Error & Beta & & \\
\hline \multirow{2}{*}{1} & (Constant) & 0.153 & 0.217 & & 0,706 & 0,482 \\
\hline & Kualitas Pelayanan & 0.949 & 0.055 & 0,866 & 17.184 & 0,000 \\
\hline
\end{tabular}

Dari tabel 8, diketahui bahwa persamaan regresi sebagai berikut :

$$
\mathrm{Y}=0.153+0.949 \mathrm{X}
$$

\section{Keterangan:}

$\mathrm{X}=$ Kualitas Pelayanan

$\mathrm{Y} \quad=$ Kepuasan Pelanggan 
Dari persamaan regresi tersebut terlihat bahwa pengaruh kualitas pelayanan terhadap kepuasan pelanggan adalah searah (positif), yang artinya bahwa peningkatan kualitas pelayanan akan mengakibatkan peningkatan terhadap kepuasan pelanggan. Hal tersebut ditunjukkan pada koefisien regresi atau nilai b dalam persamaan regresi tersebut yang menunjukkan angka positif sebesar 0,949. Arti persamaan regresi tersebut adalah jika kualitas pelayanan adalah 0 , maka nilai Y (kepuasan pelanggan) adalah sebesar 0,153 dan jika nilai kualitas pelayanan naik satu satuan maka kepuasan pelanggan akan naik sebsear 0,949 satuan.

\section{Hasil Tanggapan Wisatawan Terhadap} Loyalitas

Uji $\mathrm{t}$ bertujuan untuk melihat pengaruh variabel bebas secara parsial terhadap variabel terikat. Hipotesisnya adalah sebagai berikut:

1. Ho : Kualitas Pelayanan tidak berpengaruh secara signifikan terhadap Kepuasan Pelanggan di Restoran Jepang X

2. H1 : Kualitas Pelayanan berpengaruh secara signifikan terhadap Kepuasan Pelanggan di Restoran Jepang X

Dari tabel 8, diketahui nilai $\mathrm{t}$ hitung $=$ 17.184. Nilai $t$ tabel dapat dicari dengan ketentuan sebagai berikut:

$$
\begin{aligned}
& \alpha=0,1 \\
& \text { df = jumlah sampel (n-2) }
\end{aligned}
$$

Diketahui bahwa hasil t tabel adalah 1,29 dan dikarenakan $\mathrm{t}$ hitung (17.184) > t tabel $(1,29)$, maka Ho ditolak artinya koefisien regresi signifikan dan kesimpulannya adalah Kualitas Pelayanan berpengaruh secara signifikan terhadap Kepuasan Pelanggan di Restoran Jepang X. Maka dari itu, H1 diterima dan H0 ditolak.

\section{KESIMPULAN}

Kualitas Pelayanan di Restoran Jepang X dapat dilihat dari hasil perhitungan dimana nilai mean tertinggi yaitu 4,01 menyatakan bahwa fasilitas yang ditawarkan oleh Restoran Jepang X menarik. Oleh sebab itu Restoran Jepang X harus mempertahankan fasilitas yang ada tersebut.

Tingkat kepuasan pelanggan dapat dilihat dari hasil perhitungan dimana nilai mean sebesar 3,86, yang menyatakan Pelanggan bersedia memberi saran atau ide kepada Restoran Jepang $\mathrm{X}$ mengenai produk dan layanan. Kritik dan saran ini merupakan hal yang sangat penting untuk dievaluasi bagi Restoran Jepang X, setelah dievaluasi harus ada perbaikan agar
Restoran Jepang X dapat meningkatkan kualitas pelayanannya yang berpengaruh terhadap kepuasan pelanggannya.

Juga berdasarkan hasil penelitian dan perhitungan, dapat diambil kesimpulan yaitu terdapat hubungan yang sangat kuat antara kualitas pelayanan dan kepuasan pelanggan di Restoran Jepang X ini, yaitu sebesar 75,1\% dan $24,9 \%$ dipengaruhi oleh faktor lain yang tidak diteliti dalam penelitian ini. Diantara kedua variabel ini juga terdapat sebuah hubungan yang positif $(0,866)$ yang berarti terjadi hubungan searah antara kualitas pelayanan dengan kepuasan pelanggan. Dimana jika kualitas pelayanan mengalami peningkatan maka kepuasan pelanggan juga akan meningkat.

Hal ini sesuai dengan pernyataan dalam jurnal pengaruh kualitas pelayanan jasa terhadap kepuasan pelanggan pada CV Haspari Palembang oleh Dibyantoro dan Nani Cesimariani.(2012) yang menyatakan bahwa Pengaruh kualitas pelayanan jasa terhadap kepuasan pelanggan ini berpengaruh sangat besar yang mana pelanggan menilai seberapa baik pelayanan yang diterima dengan membandingkan apa yang diharapkan atau yang diinginkan dari pelanggan tersebut. Keberhasilan dalam memberikan layanan yang prima kepada pelanggan akan menimbulkan pandangan yang baik dari pelanggan tersebut terhadap masing-masing perusahaan dalam memberikan pelayanan secara baik.

Untuk komunikasi yang sulit dapat dilihat bahwa dalam butir pertanyaan ke 6 dan 9, keduanya mendapat mean sebesar 3.95 dan 3.90 dimana mean tersebut mendekati mean tertinggi sebesar 4.01, dapat dilihat bahwa komunikasi sudah bagus tetapi haru ditingkatkan lagi dengan cara memberikan pelatihan bahasa dan pelatihan gerak tubuh dimana hal ini akan dapat membantu para karyawan Jepang $\mathrm{X}$ untuk meningkatkan kualitas pelayanannya.

Untuk produk makanan yang telat keluar dapat dilihat pada pada butir pertanyaan ke 5 ,dimana butir ke 6 ini mendapat mean sebesar 3.93 ,hal ini mendekati mean tertinggi sebesar 4.01 , dapat dilihat bahwa penyajian makanan sudah termasuk cepat tetapi harap ditingkatkan lagi dengan mengganti dengan peralatan masak yang memadai ,mengadakan pelatihan bagaimana cara menyajikan makanan yang cepat dan mengatur waktu memasak.

Sedangkan untuk nilai mean terendah yaitu 3,73 dalam indikator kualitas pelayanan mengenai Karyawan Restoran Jepang $X$ mengetahui pelayanan yang dilakukan. Oleh karena itu, Restoran Jepang $\mathrm{X}$ harus meningkatkan pengetahuan akan pelayanan 
yang akan diberikan dengan melakukan pelatihan pelayanan, bagaimana cara memberi pelayanan yang baik , seiring dengan meningkatnya kualitas pelayanan maka akan tercipta kepuasan pelanggan yang tinggi.

Untuk variabel kepuasan pelanggan, nilai mean terendah yaitu 3,73 dengan pernyataan bahwa Pelanggan akan kembali ke Restoran Jepang X. Pernyataan tersebut menyatakan bahwa pelanggan merasa bimbang untuk kembali lagi ke Restoran Jepang X. Oleh karena itu Restoran Jepang X harus meningkatkan kualitas pelayanannya dengan cara menyajikan makanan yang cepat, menyediakan layanan dengan tepat waktu, memahami pelanggan dan berbagai cara lainnya agar pelanggan mau kembali berlangganan lagi.

Dari hasil penelitian yang menyimpulkan adanya hubungan yang sangat kuat antara kualitas pelayanan dengan kepuasan pelanggan, maka penulis merekomendasikan agar kualitas pelayanan di Restoran Jepang $\mathrm{X}$ terus dipertahankan.

Hal ini sesuai dengan pernyataan Tjiptono (2011:172) yang menyatakan bahwa kualitas berkasitan erat dengan kepuasan pelanggan. Kualitas memberikan dorongan khusus bagi para pelanggan untuk menjalin ikatan relasi saling menguntungkan dalam jangka panjang dengan perusahaan. Pada gilirannya, perusahaan dapat meningkatkan kepuasan pelanggan, dimana perusahaan memaksimumkan pengalaman pelanggan yang menyenangkan dan meminimumkan atau meniadakan pengalaman pelanggan yang kurang menyenangkan.

\section{DAFTAR RUJUKAN}

Dibyantoro dan Cesimariani, N. (2012). Pengaruh Kualitas Pelayanan Jasa Terhadap Kepuasan Pelanggan pada CV Haspari Palembang. Jurnal Ekonomi Dan Informasi Akuntansi, 2(2).

Kotler, P. (2012). Marketing Management. Jakarta: Erlangga.

Siregar, S. (2013). Statistik Parametrik untuk Penelitian Kuantitatif. Jakarta: Bumi Aksara.

Sugiyono. (2012). Metode Penelitian Kuantitatif Kualitatif dan RD. Bandung: Alfabeta.

Tjiptono, F. (2011). Service, Quality and Satisfaction. Yogyakarta: ANDI. 